\title{
Tinospora cordifolia: A Valuable Plant in Ayurveda
}

\author{
Varsha Marke, Pranali Shete and Vishal Dhundale \\ Post Graduate Department of Microbiology \\ Smt Chandibai Himathmal Mansukhani College, Ulhasnagar-421 003, India \\ E-mail: pranalikale2@gmail.com
}

\begin{abstract}
Tinospora cordifolia commonly is a natural herbal shrub that belongs to the moonseed family Menispermaceae. The phytochemical analysis showed the presence of alkaloids, flavonoid, saponins, cardiac glycosides, steroids, carbohydrate and proteins. The aqueous extracts of Tinospora cordifolia were evaluated for antibacterial activity against standard pathogens i.e. Staphylococcus aureus, Escherichia coli, Vibrio cholera, Salmonella typhi, Shigella at concentrations 5, 10 and 20\%. The 20\% aqueous extract of Tinospora cordifolia showed an optimum zone of inhibition. Vibrio cholera MTCC 3906 was highly sensitive to aqueous extract followed by S. aureus MTCC 3160 , Salmonella enterica typhi MTCC 734, Shigella sonnei, Escherichia coli MTCC 1018. Salmonella enterica typhi MTCC 734 was highly sensitive to methanol extract followed by Shigella sonnei, Staphylococcus aureus MTCC 3160, Vibrio cholera MTCC 3906, Escherichia coli MTCC 1018. These phytochemical data analysis and antibacterial activity of Tinospora cordifolia may be useful and may be lead to the improvement and formulation of drugs and discovery of drugs development against tested gastrointestinal tract pathogens.
\end{abstract}

Keywords: Tinospora cordifolia, Gastrointestinal tract pathogens, Antibacterial activity.

Ayurvedic herbs played important role in Ayurvedic treatments from ancient time to this most modern time. One of the plant known for having many medicinal use in traditional system of medicines is Tinospora cordifolia which belongs to the Menispermaceae family and is common climbing shrub in India (Shah and Shah 2016), extending from Himalayas down to the Southern Part of India. Root leaves and stem region of this shrub used for medicinal purposes and contain columbin, tinosporin, and tinosporin acid. The other different types of phytochemicals also identified which includes alkaloids, diterpenoids, lactones, steroids, glycosides, aliphatic compounds, polysaccharides, saponins, flavonoids, tannin. The $T$, cordifolia act as immunomodulatory, anti-microbial (Bonvicini et al 2014), anti-oxidant, hepatoprotection, diuretic, anti-neoplastic, antihypoglycemic, antipyretic, anti-inflammatory ( $\mathrm{Li}$ et al 2010, Tiwari et al 2014), anti-stress, anti-hyperglycemic, antidiabetic, and anti-tuberculosis also been reported (Sharma et al 2015). The stem preparation is used in general debility, dyspepsia, fevers, and urinary infection. The root is a powerful emetic and its aqueous extract is used for visceral obstruction, leprosy, etc. The present study is based on the use of its extract against certain types of pathogenic bacteria for anti-inflammatory activity.

\section{MATERIAL AND METHODS}

Collection of plant materials: The Tinospora cordifolia was collected from the Karjat Mahamandal Depo. The freshly collected stem region was then subjected to preliminary treatment, which includes washing and cutting appropriate pieces. These pieces were further dried at $54^{\circ} \mathrm{C}$ in the oven for 2-3 days and converted into powder form, which was further used for extract preparation.

Preparation of extract: For the preparation of hot water extract and methanol extract, hot water and methanol both were separately added to the powder at a ratio of 1:10. Hot water extract was heated in a boiling water bath to make the volume $3 / 4^{\text {th }}$ of the original volume. The methanol extract was kept shaker at $1500 \mathrm{rpm}$ for $48-72$ hours. Both the extract was filtered and dried at $54^{\circ} \mathrm{C}$. Then dried extract weight was determined. The extracts were stored in a cool condition to protect them from direct sunlight.

Extract quantification and sterility checking: Extract quantification was done by calculating the percent yield of the extract as:

Percent yield $=$ weight of the extract $/$ weight of the total mass of the powder $X 100$

For preliminary sterility testing of extracts, streaking was done on a sterile nutrient agar plate and sterile potato dextrose agar plate. Then the plate was incubated and observed for growth.

\section{Phytochemical Analysis}

Alkaloids: $200 \mathrm{mg}$ of plant material was dissolved in $10 \mathrm{ml}$ of methanol and filtered. To this $2 \mathrm{ml}$ filtrate, $1 \% \mathrm{HCl}$ was added and steamed, to $1 \mathrm{ml}$ of this filtrate, 6 drops of Dragendroff reagent were added and observed for orange precipitate. 
Tannins: $200 \mathrm{mg}$ plant material was mixed with $10 \mathrm{ml}$ of distilled water and then filtered. To this $2 \mathrm{ml}$ filtrate, $2 \mathrm{ml} \mathrm{FeCl}$ was added and observed for blush black precipitate.

Flavonoids: $200 \mathrm{mg}$ of plant material was heated with $10 \mathrm{ml}$ of ethyl acetate over steam and kept for $3 \mathrm{~min}$ and then filtered. To $4 \mathrm{ml}$ filtrated, $1 \mathrm{ml}$ of dilute ammonia solution was added and observed for yellow colouration.

Saponin: $200 \mathrm{mg}$ plant material mixed with $10 \mathrm{ml}$ of distilled water. The presence of frothing after shaking the tube confirms the presence of saponin.

Steroids (Libermann- Buchard reaction): 200mg plant material was mixed with $10 \mathrm{ml}$ of chloroform and filtered. To 2 $\mathrm{ml}$ of filtrate, $2 \mathrm{ml}$ of acetic anhydride then conc. $\mathrm{H}_{2} \mathrm{SO}_{4}$ was added and observed for the development of blue-green rings (Xiong et al 2007).

Cadiac glycosides (Keller - Killani test): $200 \mathrm{mg}$ plant material was mixed with $10 \mathrm{ml}$ of ethanol. To $2 \mathrm{ml}$ of this filtrate, $1 \mathrm{ml}$ of glacial acetic acid, $\mathrm{FeCl}_{3}$ and conc. $\mathrm{H}_{2} \mathrm{SO}_{4}$ were added and observed for greenish-blue colouration.

Carbohydrates: Fehling's Test for carbohydrates was performed for both water extract and methanolic extract.

Amino acids: The estimation was done by using Ninhydrin's Test for the presence of amino acids in both the extracts were tested.

Antibacterial study against gastrointestinal tract pathogens: Standard gastrointestinal tract pathogens such as Escherichia coli MTCC 1885, Salmonella enterica typhi MTCC 734, Shigella sonnei, Staphylococcus aureus MTCC 3160 and Vibrio cholera MTCC 3906were freshly subculture on sterile Nutrient Agar slant before use for antibacterial activity.

The antibacterial activity of methanol extract and water extract of Tinospora cordifolia (stem) were tested by the agar cup method. Different concentrations of both extracts $(5,10$ and $20 \%$ ) were prepared by reconstituting with $25 \%$ DMSO (Rose et al 2010). $20 \mathrm{ml}$ of sterile Nutrient Agar was bulk seeded with test culture $(0.2 \mathrm{ml}$ of $0.5 \mathrm{OD}$ culture). After solidification of agar the wells were made on this plate using $6 \mathrm{~mm}$ sterile borer (Shubha and Hiremath, 2010) and then 0.2 $\mathrm{ml}$ of extract $(5,10$ and $20 \%)$ was added. Dimethyl sulphonic acid $(25 \%)$ was used as control. The antibacterial assay

Table 1. Yield of water and methanol extract

\begin{tabular}{lccc}
\hline Methanol extract & Yield (\%) & Hot water extract & Yield (\%) \\
\hline TM1 & 11.33 & TW1 & 12.93 \\
TM2 & 11.91 & TW2 & 12.43 \\
TM3 & 11.77 & TW3 & 11.67 \\
TM4 & 12.14 & TW4 & 12.39 \\
TM5 & 11.43 & TW5 & 12.52 \\
TM6 & 11.72 & TW6 & 12.39 \\
\hline
\end{tabular}

plates were incubated at $37^{\circ} \mathrm{C}$ for $24 \mathrm{hrs}$. The diameter of the inhibition zone of was measured in $\mathrm{mm}$.

Preparation of syrup: Firstly, three different concentrations of 40,50 and $60 \%$ sugar were prepared in D/W and sterilized using an autoclave (Sivakumar et al 2011). Extract powder was added using aseptic techniques to make the final syrup concentration $10 \%$. These mixtures were homogenized using a vortex mixer. Final syrup formulations were used for antibacterial activity against $\mathrm{Gl}$ tract pathogens as used above.

Acid and bile stability of extract: For this acid and bile stability of extract, phosphate buffer of $2.5,4$ and $6 \mathrm{pH}$ were prepared to which $0.85 \%$ bile was added. In that buffer, the extract was added to make its final concentration $10 \%$. Antibacterial activity of the acid and bile subjected extract were determined at different time intervals (1,2 and $3 \mathrm{hrs})$ by using the agar cup method.

Anti-Inflammatory activity of extract: The antiinflammatory activity of the extract was studied by using the inhibition of the albumin denaturation test. The reaction mixture consists of test extract within the concentration range of 200 to $800 \mathrm{mcg} / \mathrm{ml}$ and $1 \%$ aqueous solution of bovine serum albumin. $\mathrm{pH}$ of the reaction mixture was adjusted with $1 \mathrm{~N} \mathrm{HCl}$. The sample extract was incubated at $37^{\circ} \mathrm{C}$ for $20 \mathrm{~min}$ and then heated to $51^{\circ} \mathrm{C}$ for $20 \mathrm{~min}$. After cooling the mixture, turbidity was measured at $660 \mathrm{~nm}$. The percent of inhibition of denaturation was calculated using the following equation (Dharmadeva et al 2018):

Percent inhibition $=($ Abs control - Abs sample $) X$ 100/Abs control

The aqueous extract yield was marginally higher than the methanol extract yield. This could be due to the higher polarity of water than methanol and this plant may contain more polar components. A number of different active principles including alkaloids, flavonoids, carbohydrates, saponins, steroids, cardiac glycosides and amino acids have been identified for observing its medical effect in T. cordifolia.

The phytochemical analysis done shows the presence of alkaloids, flavonoids, saponins, cardiac glycosides, steroids, carbohydrates and proteins (Table 2). All the phytochemicals were present except tannin. Amino acids were estimated with the help of Ninhydrin's Test which showed intense dark blue colouration, which could be due to the presence of a high concentration of amino acids. Test for steroids, flavonoids and cardiac glycosides also showed intense dark colouration $i$. e. present in abundant amounts. The larger foam formation points out the presence of a high amount of saponins. Other phytochemical tests gave light colour development which could indicate its intermediate and low presence in the extract. From the phytochemical 
screening, the extracts are rich in amino acid, saponin, steroids, flavonoids and cardiac glycosides. Similar results were also obtained by Sivakumar and Dhana Rajan (2011).

When tested by the well diffusion method, the aqueous extracts of leaf extracts of T.cordifolia were subjected for antibacterial activity against standard pathogens i.e. $S$. aureus, E. coli, V. cholera, S. typhi, Shigella at concentrations 5,10 and $20 \%$. as the concentration of extract increases, there was also an increase in the zone of inhibition occurs. It was found that $20 \%$ of the extract showed the highest zone of inhibition which has a $25 \mathrm{~mm}$ zone of inhibition against $V$. cholera MTCC 3906 was highly sensitive to aqueous extract and followed by $S$. aureus MTCC 3160, S. enterica typhi MTCC 734, Shigella sonnei, E. coli MTCC 1018 (Fig. 1).

This Figure 2 indicates as the concentration of methanol extract increases, there was also an increase in the zone of inhibition occur. The $20 \%$ of the extract showed the highest zone of inhibition and S. enterica typhi MTCC 734 was highly sensitive to methanol extract and showed $20 \mathrm{~mm}$ zone of inhibition followed by Shigella sonnei, S. aureus MTCC 3160, V. cholera MTCC 3906, E. coli MTCC 1018. Rose et al (2010) revealed that the maximum antibacterial activity of hot and cold methanol extracts was exhibited against Staphylococcus aureus when compared with standard drugs. Shanthi and Nelson (2013) observed that maximum inhibitory activity of ethanol extract of leaf of $T$. cordifolia was against Klebsiella pneumoniae was followed by Pseudomonas aeruginosa while the chloroform extract of leaf showed moderate activity against Pseudomonas aeruginosa and Klebsiella pneumoniae but was less against E. coli. Prajwala et al (2019) observed the antibacterial activity of $T$. cordifolia leaf extract of methanolic, ethanolic, chloroform, hexane, aqueous and acetone extract but only the methanolic extract showed the antibacterial activity against the $E$. coli. In the present study, the results of both the extract show good antibacterial activity against GI tract pathogens. In this investigation, the antibacterial activity of water extract syrup and methanol extract syrup was also evaluated against $\mathrm{Gl}$ tract pathogens. The antibacterial activity was determined for both the extract containing syrup against GI tract pathogens. As the concentration of extract increases, there was an increase in the zone of inhibition. It and 60 and $50 \%$ extract showed the highest zone of inhibition.

In the present study acid and bile tolerance of Tinospora cordifolia indicated that at different $\mathrm{pH}$ values $(2.5,4$ and 6

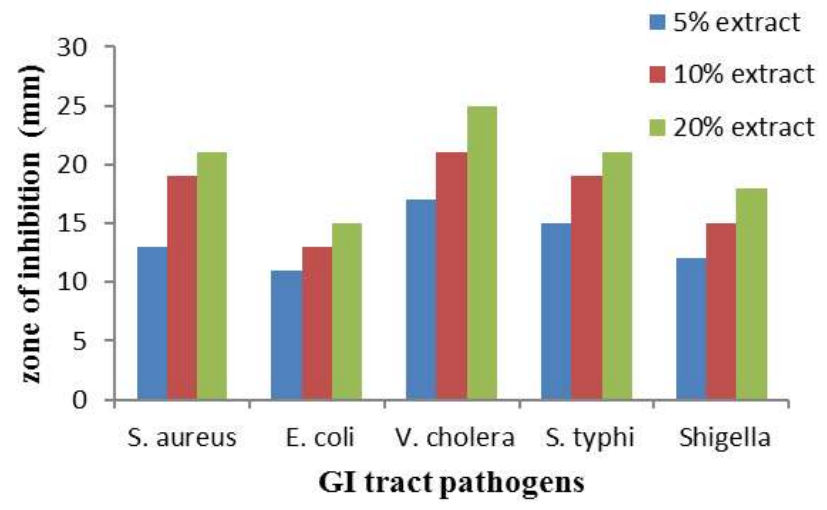

Fig. 1. Antibacterial activity of water extract against GI tract pathogens

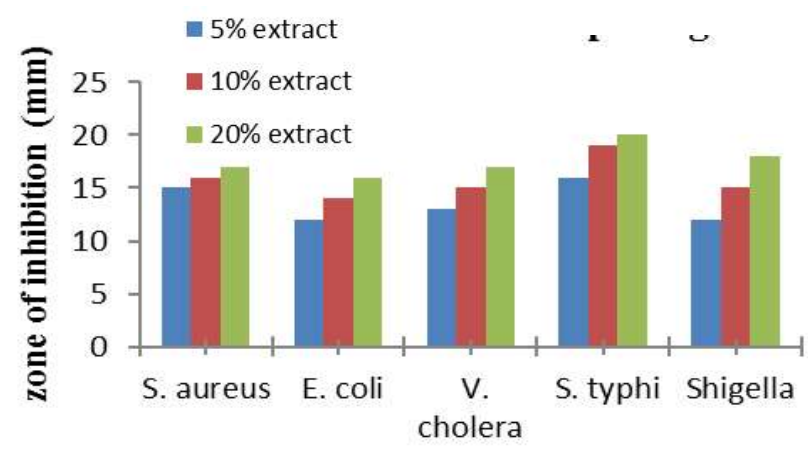

GI Tract pathogens

Fig. 2. Antibacterial activity of methanol extract against GI tract pathogens

Table 2. Phytochemical analysis of Tinospora Cordifolia

\begin{tabular}{lll}
\hline Phytochemicals & Test used & Observations/ colour \\
\hline Alkaloids & Dragendorff test & Reddish brown precipitate \\
Tannin & Ferric chloride test & Brown colour \\
Flavonoid & Alkaline reagent test & Green colour \\
Saponins & Foam formation & Foam \\
Carbohydrate & Molish test & Blue colour ring \\
Amino acid & Ninhydrin's test & Dark blue colour \\
Cardiac glycosides & Keller - Kiliani test & Greenish blue colour \\
Steroids & Libermann - Burchard test & Blue green ring \\
\hline++
\end{tabular}

+Light colour, ++ Intense dark colour, - Negative test 
Table 3. Effect of Tinospora cordifolia extract on protein denaturation

\begin{tabular}{lcc}
\hline $\begin{array}{l}\text { Concentrations } \\
\left(\mathrm{mcg} \mathrm{m}^{-1}\right)\end{array}$ & Absorbance $(540 \mathrm{~nm})$ & $\begin{array}{c}\text { \% inhibition at protein } \\
\text { denaturation }\end{array}$ \\
\hline 200 & 0.20 & 48 \\
400 & 0.25 & 34 \\
600 & 0.16 & 59 \\
800 & 0.13 & 65 \\
Control & 0.38 & -- \\
\hline
\end{tabular}

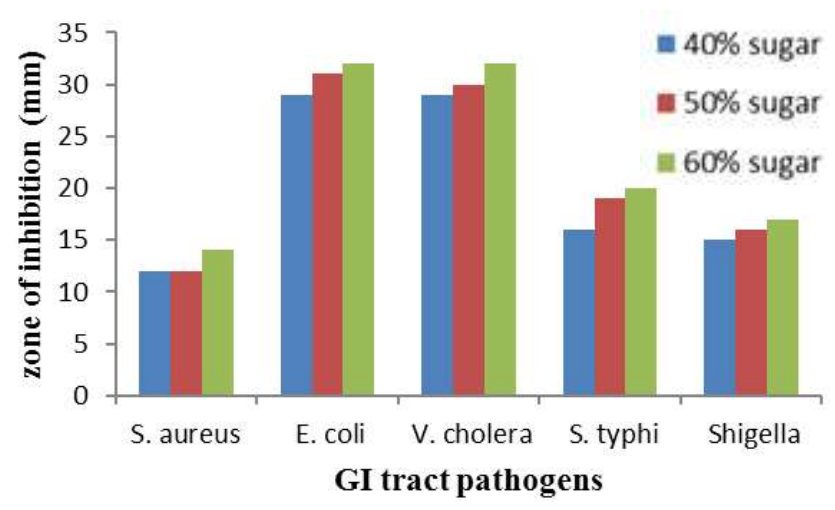

Fig. 3. Antibacterial activity of syrup (Methanol extract) against GI tract pathogens

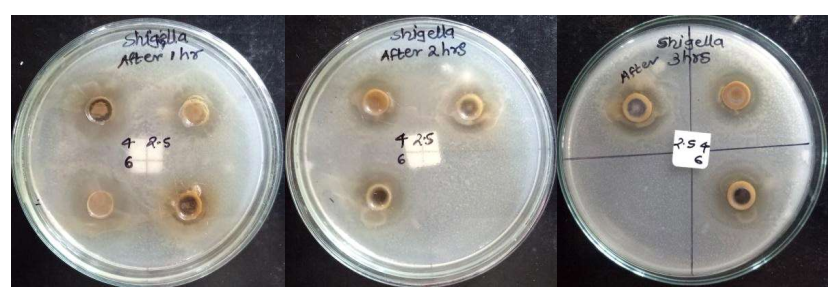

Fig. 4. Plate showing acid and bile stability of extract at different interval

$\mathrm{pH}$ ) high bile contain does not affect the activity of extract. The extract showed antibacterial activity against all the pathogens. When the extract activity was determined at different interval the activity of extract remained (Fig. 4). Both extract (water and methanol extract) at $600 \mathrm{mcg} / \mathrm{ml}$ and $800 \mathrm{mcg} / \mathrm{ml}$ showed higher inhibitory activity of protein denaturation of bovine serum albumin (Table 3).

\section{CONCLUSION}

Tinospora cordifolia may be useful due the presence of quantitative and qualitative alkaloids, flavonoid, saponins, cardiac glycosides, steroids, carbohydrates and proteins that may be lead to the improvement and formulation of drugs and discovery of drugs development against gastrointestinal tract pathogen. The $20 \%$ of the extract showed the highest zone of inhibition with $25 \mathrm{~mm}$ zone of inhibition against $V$. cholera,
MTCC 3906 was highly sensitive to aqueous extract and followed by $S$. aureus MTCC 3160, S. enterica typhi MTCC 734, Shigella sonnei, E. coli MTCC 1018. The S. enterica typhi MTCC 734 highly sensitive to methanol extract and showed $20 \mathrm{~mm}$ zone of inhibition followed by Shigella sonnei, $S$. aureus MTCC 3160 . From the present investigation, can conclude that Tinospora cordifolia has good antibacterial activity against gastrointestinal tract pathogens.

\section{REFERENCES}

Bonvicini F, Mandrone M, Antognoni F, Poli F and Gentilomi GA2014. Ethanolic extracts of Tinospora cordifolia and Alstonia scholaris show antimicrobial activity towards clinical isolates of methicillin-resistant and carbapenemase-producing bacteria. Natural Product Research 28(18): 1438-1445.

Dharmadeva S, Galgamuwa LS, Prasadinie $C$ and Kumarasinghe N 2018. In vitro anti-inflammatory activity of Ficus racemosa L. bark using albumin denaturation method. Ayu 39(4): 239-242.

Li RW, Leach DN and Myers SP 2004. Anti-inflammatory activity, cytotoxicity and active compounds of Tinospora smilacina Benth. Phytotherapy Research 18(1): 78-83.

Prajwala B, Priyanka S, Raghu N, Gopenath N, Gnanasekaran A, Karthikeyan M, Indumathi R, Ebrahim NK, Pugazhandhi B, Pradeep P, MS Ranjith, Balasubramanian S and Basalingappa KM 2019. In vitro anti-bacterial activity of Tinospora cordifolia leaf extract and its phytochemical screening. Journal of Biomedical Sciences 5(2): 10-17.

Rose FM, Noorulla KM, Asma M, Kalaichelvi R, Vadivel $\mathrm{K}$,Thangabalan $\mathrm{B}$ and Sinha BN 2010. In vitro antibacterial activity of methanolic root extract of Tinospora cordifolia (willd). International Journal of Pharma Research and Development $5(2): 1-5$.

Shah PA and Shah GB 2016. Preliminary screening of Tinospora cordifolia extracts and Guduchi satva for anti-rheumatoid activity. International Journal for Pharmaceutical Research Scholars 5(2): 7-13.

Shanthi V and Nelson R 2013. Antibacterial activity of Tinospora cordifolia (Willd) Hook. F. Thoms on urinary tract pathogens. International Journal of Current Microbiology and Applied Sciences 2(6): 190-194.

Sharma H, Galib A and Prajapati PK 2015. Antidiabetic claims of Tinospora cordifolia (Willd.) Miers: critical appraisal and role in therapy. Asian Pacific Journal of Tropical Biomedicine 5(1): 6878.

Shubha HS and Hiremath RS 2010. Evaluation of antimicrobial activity of Rasaka Bhasma Ayu. 31(2): 260-262.

Sivakumar MK, Moideen MM, Varghese R, Shatha A and Dhanapal CK 2011. Formulation and Evaluation of Herbal Syrup containing Cocos nucifera Linn. Root Research Journal of Pharmaceutical, Biological and Chemical Sciences 2(4): 53-61.

Sivakumar V and Dhana Rajan MS 2011. Standardization and Characterization of Tinospora cordifolia (Willd.) Miers ex Hook. F. \& Thoms. Plant stem extract in different solvent fractions. Asian Journal of Biochemical and Pharmaceutical Research 4(1): 105-112.

Tiwari M, Dwivedi UN and Kakkar P 2014. Tinospora cordifolia extract modulates COX-2, iNOS, ICAM-1, pro-inflammatory cytokines and redox status in murine model of asthma. Journal of Ethnopharmacology 153(2): 326-337.

Xiong Q, William K, Wilson $Æ$, Pang J 2007. The Liebermann-Burchard reaction: sulfonation, desaturation, and rearrangement of cholesterol in acid. Lipids 42: 87-96. 